\title{
SINOPSIS DE NEOMIRANDEA (ASTERACEAE: EUPATORIEAE) EN COSTA RICA
}

\author{
AlexÁnder Rodríguez G. \\ Instituto Nacional de Biodiversidad (INBio), apdo. 22-3100, Santo Domingo, Heredia, Costa Rica. \\ arodrig@inbio.ac.cr
}

Abstract. The Costa Rican species of the genus Neomirandea (Asteraceae: Eupatorieae) are treated in a synopsis. A new species is described and illustrated and its relationships are discussed.

Resumen. Se realiza una sinopsis de las especies del género Neomirandea (Asteraceae: Eupatorieae) de Costa Rica. Se describe e ilustra una nueva especie y se comentan sus afinidades.

\section{Palabras Clave / Kew words: Asteraceae, Neomirandea, Neomirandea pendulissima, Costa Rica}

Neomirandea es un género con alrededor de 28 especies, incluyendo la descrita en este trabajo, de las cuales 15 están presentes en Costa Rica. Se distribuye desde México hasta Colombia y su centro de diversificación abarca Costa Rica y Panamá.

Este género se caracteriza por estar constituido por arbustos o arbolitos pequeños, en algunos casos arbustos subescandentes; son epífitas o plantas terrestres; éstas generalmente crecen en suelos ricos en materia orgánica; además, tienen hojas opuestas, menos frecuente verticiladas, venación pinnada o palmada, capítulos discoides, con el receptáculo desnudo o cortamente pubescente, brácteas involucrales subimbricadas, las internas fácilmente deciduas, las externas persistentes, estilos a veces con la base alargada, corola a menudo pubescente en la superficie interna, constituida por células anchas, cuadradas, con las paredes laterales no situadas, aquenios prismáticos, con un vilano cerdoso (King \& Robinson 1987).

En ausencia de notas que indiquen si la especie es epífita o crece en suelos ricos en materia orgánica, algunas especies pueden resultar difíciles de identificar, incluso en el nivel genérico, principalmente las pertenecientes al subgénero Critoniopsis, las cuales no poseen la base del estilo alargado ni la corola pubescente en la superficie interna. Entre los géneros más afines a Neomirandea tenemos Critonia P. Browne y Bartlettina R. King \& H. Rob., que pertenecen a la misma tribu y comparten, entre otros caracteres, tipo de hábito, posición de hojas, tipo de capítulos, flósculos y aquenios, brácteas involucrales internas deciduas, receptáculo desnudo o pubescente, corola glabra en la superficie interna y base del estilo no alargada. Estos géneros se distinguen de Neomirandea principalmente debido a que presentan células de la corola delgadas, con las paredes laterales sinuadas.

Se han publicado varios estudios taxonómicos sobre Neomirandea, género que se basa en Eupatorium araliifolium Less. Trece especies fueron reconocidas por King \& Robinson (1970), quienes aportaron una clave dicotómica de las mismas. Entre 1972 y 1975 se publicaron 11 especies nuevas y una clave de las especies de Panamá (King \& Robinson 1975). Entre 1976 y 1985 se agregaron tres especies nuevas, de las cuales dos fueron publicadas por los autores citados.

Una sinopsis del género en Costa Rica se presenta a continuación, incluyendo una clave y la descripción de un nuevo taxon.

\section{Clave de las especies de Neomirandea de Costa Rica}

1.Hojas con el margen marcadamente serrado o lobado, envés con nervadura conspicua

2 Lámina foliar fuertemente dentada o con 5-16 lóbulos cortos e irregulares, nervadura palmada, base cordada, subcordada, obtusa a cuneada, envés con glándulas resinosas

3 Pecíolos no alados; corola con la superficie interna pubescente; ramitas terminales generalmente con tallitos y envés de las hojas densamente tomentosos N. angularis

3" Pecíolos alados, alas compuestas de dientes conspicuos, dispersos e irregulares; corola con la superficie interna glabra; ramitas terminales glabrescentes a puberulentas N. burgeri

2" Lámina foliar dentada (raras veces cortamente lobada en N. standleyi), nervadura pinnada a subpinnada, base obtusa a corto-cuneada, envés eglanduloso 
4 Arbustos terrestres, leñosos; hojas hasta 27 x $14 \mathrm{~cm}$, con 9-12 pares de nervios secundarios; capítulos con pedicelos hasta de $17 \mathrm{~mm}$ de largo, brácteas involucrales en 6-8 series, flósculos lila; aquenios 3.5-4.5 mm de largo, vilano 3/4 o del mismo largo que los flósculos. N. guevarii

4" Arbustos epífitos o sobre troncos en descomposición, sufruticosos; hojas hasta $41 \mathrm{~cm} \times 24 \mathrm{~cm}$, con 4-8 pares de nervios secundarios; capítulos con pedicelos hasta de $8.5 \mathrm{~mm}$ de largo, brácteas involucrales en 3-4 series, flósculos levemente lila a rosados; aquenios 2-2.5 mm de largo, vilano igual o escasamente más largo que los flósculos..... N. standleyi

1 Hojas con el margen entero, subentero a esparcidamente dentado, envés con nervadura conspicua a oscuramente visible

5. Hojas verticiladas, entre 3 y 4 por nudo

6 Hojas 3 por nudo, hasta $7.55 \times 2 \mathrm{~cm}$, pecíolos hasta $1 \mathrm{~cm}$ de largo, nervadura oscuramente visible, con 3-4 pares de nervios secundarios, envés con inconspicuas glándulas resinosas, en ocasiones ausentes; inflorescencias entre 5-15 x 3-15 cm, pedúnculos 2-5 cm de largo; capítulos con 4-5 flósculos, corola 4-5 mm de largo, con lóbulos glandulares; Cordilleras de Guanacaste, Tilarán y Talamanca.

N. costaricensis

6" Hojas 3 o 4 por nudo, hasta 30 x $9 \mathrm{~cm}$, pecíolos hasta $9.5 \mathrm{~cm}$ de largo, nervadura conspicua, con 8-12 pares de nervios secundarios, envés sin glándulas resinosas; inflorescencias entre 30-50 x 10-20 cm, pedúnculos 5-15 cm de largo; capítulos con 12-16 flósculos, corola 6.5-7 mm de largo, con lóbulos eglandulosos; Cordillera de Talamanca y en Puriscal-Los Santos N. pendulissima 5 " Hojas opuestas, 2 por nudo

7 Hojas con pecíolos 1.5-9 cm de largo, nervadura conspicuamente visible en ambas superficies, eglandulosas en el envés; corola esparcida a densamente pubescente en la superficie interna

8 Capítulos solitarios, con 13-24 flósculos, brácteas involucrales en 3 ó 4 series; aquenios con pelos diminutos y antrorsos en las costillas; hojas con lámina hasta 16 x $8.5 \mathrm{~cm}$, pecíolos hasta $8 \mathrm{~cm}$ de largo; 200-2150 m de elevación. N. araliifolia

8" Capítulos 3 a 8 en glomérulos o solitarios, con 1 a 6 flósculos, brácteas involucrales en 5 ó 6 series; aquenios glabros, menos frecuente con pelos diminutos y antrorsos en las costillas; hojas con lámina hasta 10.5 x $6.5 \mathrm{~cm}$, pecíolos hasta $4.5 \mathrm{~cm}$ de largo; 1100-3150 m de elevación

9 Capítulos solitarios o 2 ó 3 por glomérulo, pedúnculos 1-5 mm de largo, con 4-6 flósculos; aquenios glabros; envés de las hojas nunca barbado; 1100-3150 m de elevación. N. turrialbae

9" Capítulos 3 a 8 por glomérulo, sésiles o subsésiles, con 1 ó 2 flósculos; aquenios glabros a pubescentes en las costillas; envés de las hojas en ocasiones barbado en las axilas entre el nervio central y los secundarios; 2300-3000 m de elevación. N. psoralea

7' Hojas subsésiles o pecíolos hasta $1.5 \mathrm{~cm}$ de largo (excepto $N$. arthodes hasta $4.5 \mathrm{~cm}$ de largo), nervadura obscura a conspicuamente visible en ambas superficies, con o sin glándulas en el envés; corola sin pelos en la superficie interna

10 Hojas subsésiles o pecíolos hasta $0.4 \mathrm{~cm}$ de largo, ápice obtuso o agudo; brácteas involucrales internas hasta $2.75 \mathrm{~mm}$ de largo; corola con esparcidas glándulas resinosas sobre toda la superficie externa N. allenii

10" Hojas pecioladas, pecíolos hasta $3.5 \mathrm{~cm}$ de largo, ápice agudo o acuminado (raras veces obtuso en $N$. eximia); brácteas involucrales internas hasta $8 \mathrm{~mm}$ de largo; corola sin glándulas sobre la superficie externa, si presentes entonces únicamente en el lado externo de los lóbulos

11 Capítulos con 12 a 15 flósculos; brácteas involucrales en 5 ó 6 series, las externas ovadoorbiculares, hasta $2.25 \mathrm{~mm}$ de ancho, las internas hasta $8 \mathrm{~mm}$ de largo

12 Tallitos sólidos o fistulosos; hojas eglandulosas en el envés; pecíolos hasta $3.5 \mathrm{~cm}$ de largo; capítulos con pedicelos hasta $7 \mathrm{~mm}$ de largo, con 11 ó 12 flósculos, lóbulos de la corola eglandulosos; aquenios glabros. N. arthodes

12" Tallitos sólidos; hojas con glándulas resinosas en el envés (al menos en hojas nuevas); pecíolos hasta $1 \mathrm{~cm}$ de largo; capítulos con pedicelos hasta $20 \mathrm{~mm}$ de largo, con 12 a 15 flósculos, lóbulos de la corola glandulares; aquenios con pelos diminutos y antrorsos en las costillas N. carnosa

11" Capítulos con 4 a 10 flósculos; brácteas involucrales en 3 ó 4 series, las externas 
oblongas a oblongo-ovadas, hasta $1.25 \mathrm{~mm}$ de ancho, las internas hasta $5 \mathrm{~mm}$ de largo 13 Inflorescencias 10-35 cm x 6-36 cm; capítulos con 7 a 10 flósculos, pedicelos hasta $18 \mathrm{~mm}$ de largo; entrenudos de ramitas terminales con hojas reducidas y similares a escamas N. eximia

13" Inflorescencias 4-20 x 4-20 cm; capítulos con 4 ó 5 flósculos, pedicelos hasta $12 \mathrm{~mm}$ de largo; entrenudos de ramitas terminales carentes de hojas reducidas y similares a escamas

14 Ramitas terminales y ejes de inflorescencias esparcida, densa y cortamente pilosos; hojas hasta $12.5 \times 5.5 \mathrm{~cm}$; pecíolos hasta $1.5 \mathrm{~cm}$ de largo; nervios secundarios en 5 a 8 pares, fácilmente visibles en el envés; aquenios glabrescentes; 1500-2000 m de elevación N. croatti

14" Ramitas terminales glabrescentes, ejes de la inflorescencia esparcidamente puberulentos; hojas hasta $8.5 \mathrm{~cm} \times 3 \mathrm{~cm}$; pecíolos hasta $0.8 \mathrm{~cm}$ de largo; nervios secundarios en 2 ó 3 pares, oscuramente visibles en el envés; aquenios glabros o con diminutos y antrorsos pelos sobre las costillas; 550-1300 m de elevación N. parasitica

Neomirandea allenii R.M. King \& H. Rob., Rhodora 74 (798): 273-274. 1972.

Distribución. Costa Rica a Colombia. En Costa Rica la encontramos en los bosques muy húmedos de la vertiente caribe de la Cordillera de Talamanca, alrededor de $700 \mathrm{~m}$ de elevación.

Fenología. Flores en julio.

Neomirandea allenii se distingue de las otras especies del género presentes en Costa Rica por sus reducidos pecíolos, los cuales son casi obsoletos o no sobrepasan $4 \mathrm{~mm}$ de largo, por el ápice de las hojas obtuso o agudas y por sus flósculos esparcidamente glándular-resinosos en toda la superficie externa; además, se distingue por ser un arbusto epífito, con hojas enteras a diminutamente denticuladas, nervadura pinnada, brácteas involucrales externas oblongas a oblongo-ovadas, flósculos glabros en la superficie interna y por los aquenios esparcidamente pilosos. En Costa Rica se conocen solamente dos especímenes de esta especie. Se podría confundir con las afines $N$. eximia y $N$. parasitica, aunque éstas se distinguen fácilmente por los pecíolos más largos, entre 2 y 12 $\mathrm{mm}$.

Especímenes Representativos eXaminados. COSTA RICA. Limón: Talamanca, Croriña, camino a Amubri, Quebrada Crori y Quebrada Lumbeta., $09^{\circ} 25^{\prime} 15^{\prime}$ 'N, 82 59'00”'W, 800 m, 13 jul 1989, A. Chacón 167 (CR); fila de exploración minera entre el Río Sukut y Río Carbri, Muragubishi, $09^{\circ} 22^{\prime} 50^{\prime \prime} \mathrm{N}, 82^{\circ} 56^{\prime} 50^{\prime \prime} \mathrm{W}, 700$ m, 14 jul 1989, G. Herrera 3285 (CR, INB).

Neomirandea angularis (B.L. Rob.) R.M. King \& H. Rob., Phytologia 19: 307. 1970.
Eupatorium angulare B.L. Rob., Contr. Gray Herb. 96: 19. 1931. E. fistulosum B.L. Rob., Proc. Boston Soc. Nat. Hist. 31: 249. 1904.

Distribución. Endémica en Costa Rica. Se encuentra en bosques húmedos y pluviales de la vertiente pacífica en Puriscal-Los Santos y en ambas vertientes en las Cordilleras de Guanacaste, Tilarán, Central y de Talamanca, 400-2350 m de elevación.

Fenología. Flores en abril y entre julio y noviembre.

Neomirandea angularis se reconoce por ser un arbusto terrestre, con pubescencia densamente tomentosa en ramitas terminales, hojas ampliamente ovadas, a menudo con un gran número de lóbulos cortos, con nervadura palmada a subpalmada, envés con abundantes glándulas resinosas y flósculos pubescentes en la superficie interna. Esta especie es afín a $N$. burgeri; sin embargo, esta última presenta pecíolos alados, los flósculos son glabros en la superficie interna y las partes vegetativas generalmente glabrescentes. Otras especies relacionadas son $N$. panamensis R.M. King \& H. Rob. y N. folsomiana M.O. Dillon \& D'Arcy, ambas endémicas en Panamá.

EsPeCímenes RePresentativos eXaminados. COSTA RICA. Alajuela: San Ramón, Cordillera de Guanacaste, Monteverde, San Gerardo Biological Station, trail to Garden, $500 \mathrm{~m}$ E of Station, $10^{\circ} 22^{\prime} \mathrm{N}, 84^{\circ} 48^{\prime} \mathrm{W}$, 1200 m, 1 Jul 1995, D. Penneys 567 (INB). Cartago: Cartago, Reserva Forestal de Río Macho, Río Queveri, camino al ICE, 9 ${ }^{\circ} 42^{\prime} 50^{\prime \prime} \mathrm{N}, 83^{\circ} 50^{\prime} 10^{\prime \prime} \mathrm{W}, 2200 \mathrm{~m}, 22$ abr 1998, E. Alfaro 1528 (INB); El Guarco, La Sierra,

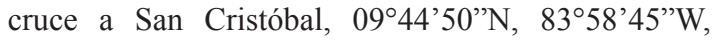
1900-2005 m, 19 sept 1987, A. Rodríguez 2481 (INB). 
Heredia: Sarapiquí, Rara Avis, cerca $15 \mathrm{~km}$ al SO de Horquetas, $10^{\circ} 17^{\prime} \mathrm{N}, 8^{\circ} 02^{\prime} \mathrm{W}, 400-600 \mathrm{~m}, 28$ nov 1989, O. Vargas 330 (INB). San José: Aserrí, Zona Protectora Cerros de Escazú, El Cedral, 0950'55”N, 8407'55”'W, 2350 m, 11 sept 1993, J.F. Morales 1715 (INB).

Neomirandea araliifolia (Less.) R.M. King \& H. Rob., Phytologia 19: 307. 1970.

Eupatorium araliifolium Less., Linnaea 6: 403-404. 1831.

Distribución. México a Panamá. En Costa Rica se le encuentra en los bosques húmedos, muy húmedos y pluviales de la vertiente pacífica en Puriscal-Los Santos y en ambas vertientes en las Cordilleras de Guanacaste, Tilarán, Central y de Talamanca, 200$2150 \mathrm{~m}$ de elevación.

Fenología. Flores entre diciembre y abril.

Neomirandea araliifolia se reconoce por ser un arbusto epífito o terrestre, con hojas enteras a denticuladas, pecíolos alargados, nervadura pinnada, con nervios visibles, eglandulosas en el envés de la lámina, flósculos pubescentes en la superficie interna y aquenios con diminutos y antrorsos pelos en las costillas. Muy similar a N. psoralea y a N. turrialbae, de las cuales resulta muy difícil de distinguir en condición estéril; se diferencia ya que estas últimas poseen capítulos con menor número de flósculos, entre 1 y 6 (vs. 13 a 24 flósculos). Además, N. psoralea a menudo tiene el envés de las hojas barbado en las axilas entre el nervio central y los secundarios y capítulos sésiles o subsésiles en glomérulos.

ESPECÍMENES REPRESENTATIVOS EXAMINADOS. COSTA RICA. Alajuela: San Carlos, Cordillera de Tilarán, Fortuna al Lago Arenal, 10²9'40”N, 8443'20"W, 500 m, 2 abr 1994, B. Hammel 19555 (INB). Limón: Cordillera de Talamanca, Reserva Biológica Hitoy Cerere, $300 \mathrm{~m}$ aguas debajo de la confluencia del Río Hitoy Cerere, margen izquierda por la fila que lleva al Cerro Bobócara, 09³9'00”N, 8302'45”W, 200 m, 20 abr 1989, G. Herrera 2428 (INB). Puntarenas: Coto Brus, Parque Internacional La Amistad, Cordillera de Talamanca, Estación Pittier, Sendero Altamira,

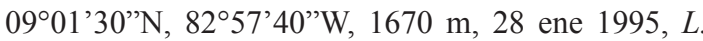
Angulo 3 (INB); Puntarenas, Cordillera de Tilarán, Monteverde, Sendero Tranquilo, $1.5 \mathrm{~km}$ SE of Cerro Amigos, $10^{\circ} 18^{\prime} \mathrm{N}, 8^{\circ} 48^{\prime} \mathrm{W}, 1400 \mathrm{~m}, 27$ Febr 1995, D. Penneys 174 (INB). San José: Aserrí, Zona Protectora
Cerros de Escazú, El Cedral, 0950'30”N, 8406’35”W, 2105 m, 30 dic 1993, J.F. Morales 2190 (INB).

Neomirandea arthodes (B.L. Rob.) R.M. King \& H. Rob., Phytologia 19: 308. 1970.

Eupatorium arthodes B.L. Rob., Contr. Gray Herb. 68: 8. 1923.

Distribución. Costa Rica y Panamá. En Costa Rica se encuentra en bosques pluviales de ambas vertientes de la Cordillera de Talamanca, 1300-1900 m de elevación.

FenOlogía. Flores en julio.

Neomirandea arthrodes se reconoce por ser un arbusto escandente a subescandente, terrestre, con hojas cortamente denticuladas, eglandulosas, nervadura pinnada, con nervios oscuramente visibles en el envés, capítulos con brácteas involucrales externas ovadoorbiculares y flósculos glabros en la superficie interna. Esta especie se encuentra muy relacionada con $N$. carnosa; sin embargo, esta última presenta hojas con glándulas resinosas en el envés (al menos en hojas nuevas), lóbulos de la corola glandulares, pecíolos más cortos, hasta $10 \mathrm{~mm}$ de largo (vs. 2 a $45 \mathrm{~mm}$ de largo) y pedicelos más largos, hasta $20 \mathrm{~mm}$ (vs. 1 a 7 $\mathrm{mm}$ ). También se podría comparar con $N$. araliifolia, $N$. eximia y $N$. psoralea.

Especímenes Representativos examinados. COSTA RICA. Cartago: Paraíso, Parque Nacional Tapantí, camino a la represa Tapantí, en borde de la carretera, $09^{\circ} 45^{\prime} 20^{\prime \prime} \mathrm{N}, 83^{\circ} 47^{\prime} 00^{\prime \prime} \mathrm{W}, 1300 \mathrm{~m}, 20$ jul 1994, Q. Jiménez 1614 (INB); El Guarco, Cordillera de Talamanca, bosque residual en el cruce de San Cristóbal Norte, $09^{\circ} 46^{\prime} 54^{\prime \prime N}, 8^{\circ} 59^{\prime} 36^{\prime \prime} W, 1900$ m, 18 jun 1997, J.F. Morales 6198 (INB). Heredia: Reserva Forestal Cordillera Volcánica Central, refugio Cerro Dantas, Cerro Chompipe, $10^{\circ} 05^{\prime} 12^{\prime \prime} \mathrm{N}$, 8403'32”W, 1800 m, 6 jul 2002, R. Kriebel 391 (INB).

Neomirandea burgeri R.M. King \& H. Rob., Phytologia 24(4): 282-283. 1972.

Neomirandea grosvenorii R.M. King \& H. Rob., Phytologia 29(5): 354-356. 1975.

Distribución. Endémica en Costa Rica. Se encuentra en bosques pluviales de la vertiente caribe en las Cordilleras Central y de Talamanca; también en la vertiente pacífica de la Cordillera de Talamanca y en los Cerros de Escazú, 2300-2750 m de elevación. 
Fenología. Flores en febrero, abril, julio, septiembre y diciembre.

Neomirandea burgeri se distingue de las otras especies del género que habitan en Costa Rica por presentar pecíolo alados, en los que las alas consisten de dientes irregulares y dispersos a lo largo del pecíolo; además, se distingue por ser un arbusto terrestre, con hojas ampliamente ovadas, irregularmente lobadas, nervadura palmada a subpalmada, envés con glándulas resinosas y flósculos glabros en la superficie interna. Esta especie es afín a $N$. angularis; sin embargo, esta última nunca tiene pecíolos alados, los flósculos son pubescentes en la superficie interna y las partes vegetativas son generalmente más pubescentes. Otras especies relacionadas son $N$. panamensis y $N$. folsomiana, ambas endémicas en Panamá, pero ambas se distinguen porque no muestran el pecíolo alado o éste es levemente alado en la parte distal. Esta especie también podría compararse con $N$. standleyi.

EsPecímenes REPRESENTATIVOS EXAMINAdos. COSTA RICA. Heredia: Upper Volcán Barva, Atlantic Slope ca. $0.5 \mathrm{~km}$ below (to $\mathrm{N}$ of ) main trail to Laguna Barva descending via old Sendero del transecto, $10^{\circ} 08^{\prime} 18^{\prime \prime} \mathrm{N}, 84^{\circ} 06^{\prime} 33^{\prime \prime} \mathrm{W}, 2750 \mathrm{~m}, 28$ Abr 1992, B. Boyle 800 (CR); Limón: Cordillera de Talamanca, Atlantic slope, unnamed cordillera between the Río Terbi and the río Siní, $09^{\circ} 06^{\prime} \mathrm{N}, 82^{\circ} 58^{`} \mathrm{~W}, 2650 \mathrm{~m}, 13$ Sept 1984, G. Davidse 29056 (CR); San José: Zona Protectora Cerros de Escazú, El Cedral, 0951'21'N, 8408'36”'W, 2300 m, 15 jul 2004, A. Estrada \& G.

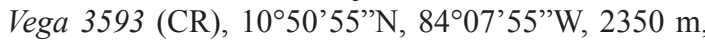
11 sept 1993, J.F. Morales 1715 (CR, INB).

Neomirandea carnosa (Kuntze) R.M. King \& H. Rob., Phytologia 19: 308. 1970.

Eupatorium carnosum Kuntze, Revis. Gen. Pl. 1: 337. 1891.

Distribución. Costa Rica y Panamá. En Costa Rica se le encuentra en bosques pluviales de la vertiente caribe de la Cordillera de Talamanca; en la vertiente pacífica en la Fila Costeña sur y en la Cordillera de Guanacaste, 1300-1900 m de elevación.

Fenología. Flores entre junio y noviembre.

Neomirandea carnosa se distingue por ser un arbusto epífito, con hojas enteras a denticuladas, glandulares, con nervadura pinnada, oscuramente visibles en el envés, brácteas involucrales externas ovadoorbiculares y flósculos glabros en la superficie interna.
Esta especie está muy relacionada con $N$. arthrodes; sin embargo, esta última carece de glándulas resinosas en el envés de la lámina, sus pecíolos y pedicelos podrían llegar a ser más largos y los lóbulos de la corola son eglandulosos. También podría compararse con N. araliifolia, N. eximia y N. psoralea.

Especímenes Representativos examinados. COSTA RICA. Alajuela, Upala, Parque Nacional Volcán Tenorio, Estación Biológica Heliconia, $10^{\circ} 42^{\prime} 10^{\prime} \mathrm{N}$, 8502'40”'W, 718 m, 19 jul 2001, J.L. Chávez 1250 (INB); sector Alto Los Brenes, $10^{\circ} 43^{\prime} 08^{\prime} \mathrm{N}$, 8502'13”W, 650 m, 21 ago 2001, J.L. Chávez 1299 (INB). Guanacaste: La Cruz, Santa Cecilia $9 \mathrm{~km} \mathrm{~S}$, $08^{\circ} 45^{\prime} \mathrm{N}, 83^{\circ} 09^{\prime} \mathrm{W}, 1200$ m, 20 ago 1993, V. Ramírez 67 (INB); Parque Nacional Guanacaste, Estación Pitilla, Fila Orosilito y Sendero Nacho, $11^{\circ} 02^{\prime} 00^{\prime} \mathrm{N}$, 85²4'30"W, 700 m, 12 nov 1990, P. Ríos 202 (INB); Puntarenas: Golfito, Fila Costeña, $8^{\circ} 45^{\prime} \mathrm{N}, 83^{\circ} 09^{\prime} \mathrm{W}$, 650 m, 6 abr 1997, W. Huber \& A. Weissenhofer 756 (INB).

Neomirandea costaricensis R.M. King \& H. Rob., Phytologia 19: 308. 1970.

Distribución. Costa Rica y Nicaragua. En Costa Rica se le encuentra en bosques pluviales de ambas vertientes en las Cordilleras de Guanacaste, Tilarán, Central y de Talamanca, 400-2350 m de elevación.

Fenología. Flores entre abril y octubre.

Neomirandea costaricensis se distingue de las otras especies del género presentes en Costa Rica por presentar hojas verticiladas (carácter compartido con $N$. pendulissima), con 3 hojas por nudo; además, es un arbusto epífito, con nervios de las hojas oscuramente visibles en el envés, brácteas involucrales con glándulas resinosas, flósculos glabros en la superficie interna y lóbulos de la corola glandular-resinosos. Se podría comparar con $N$. pendulissima, la cual se distingue por tener 3 ó 4 hojas por nudo y lámina foliar e inflorescencias más grandes (ver adelante comentarios sobre esta última). También es similar a $N$. parasitica, la cual se distingue fácilmente debido a que posee hojas opuestas, nunca verticiladas.

EsPecímenes Representativos eXAminados. COSTA RICA. Cartago: El Guarco, Parque Nacional TapantíMacizo de la Muerte, La Esperanza del Guarco, 09॰41'35”N, 8352'03”'W, 2840 m, 21 abr 1999, M. Alfaro 125 (INB). Guanacaste: Parque Nacional Guanacaste, Estación Mengo, Volcán Cacao, $10^{\circ} 55^{\prime} \mathrm{N}$, 
$85^{\circ} 28^{\prime} \mathrm{W}, 1250 \mathrm{~m}, 15$ jul 1989, I INBio 190 (INB). Heredia: San Rafael, Reserva Forestal Cordillera Volcánica Central, Cerro Chompipe, $10^{\circ} 05^{\prime} 13^{\prime \prime N}$, 8404'23”'W, 2100 m, 16 mayo 1997, B. Gamboa 1399 (INB); Parque Nacional Braulio Carrillo, Volcán Barva, $10^{\circ} 08^{\prime} 05^{\prime} \mathrm{N}, 8^{\circ} 06^{\prime} 20^{\prime \prime} \mathrm{W}, 2800 \mathrm{~m}, 6$ oct 1989 , G. Rivera 75 (INB). San José: Dota, Reserva Forestal Los Santos, camino a Providencia de Dota, 9'36'37'N 8349’33”W, 2900 m, 25 jun 1997, B. Gamboa 1581 (INB).

Neomirandea croatii R.M. King \& H. Rob., Phytologia 29(5): 352-353. 1975.

Distribución. Costa Rica y Panamá. En Costa Rica se encuentra en los bosques pluviales de la vertiente caribe de la Cordillera de Talamanca y en la vertiente pacífica de la Cordillera de Tilarán, 1500-2000 m de elevación.

Fenología. Flores en marzo y abril.

Neomirandea croatii se distingue de las otras especies del género presentes en Costa Rica por presentar tallitos densa y cortamente hirsutos; además, es un arbusto epífito, a veces crece sobre troncos en descomposición, tiene lámina foliar con el margen denticulado y nervadura pinnada, capítulos con brácteas involucrales externas oblongas a oblongoovadas y flósculos glabros en la superficie interna. Se podría comparar con $N$. costaricensis, $N$. eximia y $N$. parasitica, que se diferencian por mostrar tallitos glabrescentes o apenas puberulentos.

ESPECímenes REPRESENTATIVOS EXAMINADOS. COSTA RICA. Guanacaste: Tilarán, Cordillera de Tilarán, $1 \mathrm{~km}$ SW from Santa Elena Reserve, along road, $10^{\circ} 20^{\prime} \mathrm{N}, 84^{\circ} 48^{\prime} \mathrm{W}, 1500 \mathrm{~m}, 26$ Mar 1995, D. Penneys 284 (INB). Limón: Talamanca, Cordillera de Talamanca, Quebrada Kuisa, de unión del Río Lori hasta el Sendero de Ujarrás a San José Cabécar, $09^{\circ} 22^{\prime} 55^{\prime \prime} \mathrm{N}, 83^{\circ} 14^{\prime} 10^{\prime \prime} \mathrm{W}, 2000 \mathrm{~m}, 25$ mar 1993 , A. Fernández 834 (INB). Puntarenas: Puntarenas, Cordillera de Tilarán, Reserva Biológica Monteverde, Estación El Valle, $10^{\circ} 18^{\prime} 45^{\prime \prime} \mathrm{N}, 84^{\circ} 46^{\prime} 23^{\prime \prime} \mathrm{W}, 1500$ m, 21 abr 1995, A. Azofeifa 84 (INB); Santa Elena, Sendero Orquídeas, $10^{\circ} 08^{\prime} 16^{\prime \prime N}, 84^{\circ} 47^{\prime} 55^{\prime} \mathrm{W}, 1520$ m, 15 mar 1996, K. Martinez 555 (INB).

Neomirandea eximia (B.L. Rob.) R.M. King \& H. Rob., Phytologia 19: 309. 1970.

Eupatorium eximium B.L. Rob., Contr. Gray Herb. 73: 11. 1924.
Distribución. Costa Rica y Panamá. En Costa Rica se encuentra en bosques muy húmedos y pluviales de ambas vertientes en las Cordilleras de Guanacaste, Tilarán, Central y de Talamanca, 70-2500 m de elevación.

Fenología. Flores entre enero y abril, además en agosto y noviembre.

Neomirandea eximia se distingue de las otras especies del género por mostrar frecuentemente entrenudos de ramitas terminales con hojas reducidas y similares a escamas, producto de un aparente crecimiento abortivo de las hojas; además, es un arbusto epífito, sólo ocasionalmente terrestre, hojas con el margen entero a diminutamente denticulado, nervios la mayoría oscuramente visibles en el envés, nervadura pinnada, capítulos con brácteas involucrales externas oblongoovadas y flósculos glabros en la superficie interna. Esta especie es muy variable en cuanto a presencia y abundancia de glándulas resinosas en el envés de las hojas, brácteas involucrales y flósculos; también la pubescencia en aquenios es variable.

Neomirandea eximia podría compararse con $N$. arthrodes, $N$. carnosa, $N$. croatii y $N$. parasitica; de éstas es difícil de distinguir vegetativamente (ver la clave y las discusiones pertinentes). También, es similar a $N$. chiriquensis R.M. King \& H. Rob., especie endémica en Panamá; sin embargo, se diferencian debido a que en esta última los entrenudos de las ramitas terminales carecen de hojas reducidas y la lamina foliar generalmente es más ancha, hasta $6.5 \mathrm{~cm}$ (vs. hasta $4 \mathrm{~cm}$ ).

ESPECímenes REPRESENTATIVOS EXAMINAdos. COSTA RICA. Cartago: Paraíso, Parque Nacional Tapantí, alrededores de la estación, $09^{\circ} 45^{\top} \mathrm{N}, 83^{\circ} 47^{\prime} \mathrm{W}, 1200$ m, 27 febr 1997, A. Rodríguez 2035 (INB). Limón: Limón, El Progreso, siguiendo la fila a Cerro Matama, $09^{\circ} 47^{\prime} 20^{\prime \prime} \mathrm{N}, 8^{\circ} 07^{\prime} 30^{\prime \prime} \mathrm{W}, 1600 \mathrm{~m}, 23$ abr 1989, G. Herrera 2742 (INB). Puntarenas: Buenos Aires, Parque Nacional La Amistad, sendero a Cerro Cabécar, $09^{\circ} 20^{\prime} 43^{\prime \prime} \mathrm{N}, 83^{\circ} 22^{\prime} 54^{\prime \prime} \mathrm{W}, 2800 \mathrm{~m}, 8$ sept 2000 , A. Alfaro 3371 (INB); Cerro Hoffmann, $09^{\circ} 06^{\prime} \mathrm{N}$, 8259'W, 2000-2500 m, 7 ago 1997, J. Quesada 1980 (INB); Puntarenas, Cordillera de Tilarán, San Luis, Río Veracruz, Monteverde, $10^{\circ} 15^{\prime} 10^{\prime \prime} \mathrm{N}, 84^{\circ} 47^{\prime} 30^{\prime \prime} \mathrm{W}$, 1100 m, 22 nov 1993, Z. Fuentes 576 (INB).

Neomirandea guevarii R.M. King \& H. Rob., Phytologia 24(4): 283-284. 1972.

Distribución. Endémica en Costa Rica. Se le encuentra 
en bosques pluviales de la vertiente caribe en las Cordilleras de Tilarán, Central y de Talamanca, 1300$1600 \mathrm{~m}$ de elevación.

Fenología. Flores en febrero y marzo.

Neomirandea guevarii se reconoce por ser un arbusto terrestre, con hojas gruesa e irregularmente dentadas, nervadura pinnada, fácilmente visible en ambas superficies, inflorescencias amplias y flósculos pubescentes en la superficie interna.

ESPECímENES REPRESENTATIVOS EXAMINADOS. COSTA RICA. Alajuela: Reserva Biológica Monteverde Atlantic slope, $10^{\circ} 18^{\prime} \mathrm{N}, 84^{\circ} 46^{\prime} \mathrm{W}, 1250-1550 \mathrm{~m}, 1$ Mar 1992, W. Haber 11038 (INB). Cartago: Paraíso, Parque Nacional Tapantí-Macizo de la Muerte, Alto El Roble, 0943'35'N, 8351'24”W, 2140 m, 16 mar 2002, E. Alfaro 3914 (INB); Estación Tapantí, Río Grande de Orosi, sector la represa, $09^{\circ} 45^{\prime} 20^{\prime} \mathrm{N}$, $83^{\circ} 47^{\prime} 00^{\prime \prime} \mathrm{W}, 1300 \mathrm{~m}, 8$ mar 1995, G. Mora 528 (INB); bosque primario en el Sendero Árboles Caídos,

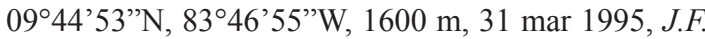
Morales 3822 (INB). Limón: Talamanca, Cordillera de Talamanca, along Quebrada Kuisa, (triburary of Río Lori) near crossing of Ujarrás-San José Cabécar trail, 09²0’30”N, 8314'00”'W, 2100 m, 13 Mar 1993, M. Grayum 10284 (INB).

Neomirandea parasitica (Klatt) R.M. King \& H. Rob., Phytologia 19: 309. 1970.

Eupatorium parasiticum Klatt, Ann. K.K. Naturhist. Hofmus. 9: 357. 1894.

Distribución. Endémica en Costa Rica. Se encuentra en bosques pluviales sobre ambas vertientes en las Cordilleras de Guanacaste y Tilarán, 550-1300 m de elevación.

Fenología. Flores la mayor parte del año.

Neomirandea parasitica se reconoce por ser un arbusto epífito o crecer en troncos en descomposición, por presentar hojas pequeñas, hasta $8.5 \mathrm{~cm}$ de largo y $3 \mathrm{~cm}$ de ancho, con el margen subentero a denticulado, nervios oscuramente visibles en el envés, nervadura pinnada, capítulos con brácteas involucrales externas oblongo-ovadas y flósculos glabros en la superficie interna. Esta especie en ocasiones se confunde con $N$. costaricensis, pero esta última presenta hojas ternadas. También es muy afín a $N$. eximia y probablemente se hibridiza con ésta; se distinguen porque $N$. parasitica posee capítulos con menor número de flósculos, entre 4 y 5 (vs. 7 a 10 flósculos). En la Flora de Nicaragua
(Turner 2001) se incluyó esta especie erróneamente, ya que el único espécimen citado por el autor (Neill 2314, MO) y tratado como Eupatorium parasiticum Klatt corresponde realmente a $N$. costaricensis.

Especímenes Representativos eXaminados. COSTA RICA. Alajuela: Guatuso, Parque Nacional Volcán Tenorio, El Pilón, sector Los Teñideros, $10^{\circ} 42^{\prime} 16^{\prime} \mathrm{N}$, 8459'32”W, 800 m, 9 jul 2000, J.L. Chávez 608 (INB); Upala, Parque Nacional Guanacaste, Estación San Ramón, Dos Ríos, Sendero El Argentino, $10^{\circ} 52^{\prime} 50^{\prime \prime} \mathrm{N}, 85^{\circ} 24^{\prime} 05^{\prime \prime} \mathrm{W}, 550 \mathrm{~m}, 27$ ene 1995, $F$. Quesada 207 (INB). Guanacaste: Liberia, Parque Nacional Guanacaste, Estación Cacao, Sendero Maritza, $10^{\circ} 55^{\prime} 43^{\prime} \mathrm{N}, 8^{\circ} 28^{\prime} 10^{\prime} \mathrm{W}, 1100 \mathrm{~m}, 9$ febr 1995, L. Angulo 73 (INB); Estación Pitilla, Sendero Nacho, $11^{\circ} 02^{\prime} 00^{\prime}$ 'N, $85^{\circ} 24^{\prime} 30^{\prime \prime} \mathrm{W}, 700$ m, 2 febr 1991 , P. Ríos 334 (INB); Tilarán, 1-2 km west of Lago de Cote, $13 \mathrm{~km}$ north of Tilarán, $10^{\circ} 35^{\prime} \mathrm{N}, 84^{\circ} 56^{\prime} \mathrm{W}, 800$ 900 m, 24 Aug 1993, W. Haber 11655 (INB).

\section{Neomirandea pendulissima Al. Rodr., sp. nova}

Tipo: Costa Rica. Puntarenas: Coto Brus, Parque Internacional La Amistad, Estación Pittier, Río Cotón, Aguas Calientes, 0901'30’N, 8257'40”W, $1000 \mathrm{~m}$, 1 febr 1995, L. Angulo \& IV Curso de Parataxónomos 26 (holotipo: INB, isotipos: CR, MO). Fig. 1.

A congeneribus verticillis foliorum usque tri-vel quadrifoliatis vestitis et inflorescentiis longioribus pendulisque differt.

Arbusto leñoso, epífito. Tallitos teretes, estriados, glabros, sólidos, no fistulosos. Hojas verticiladas, entre 3 y 4 por nudo; pecíolos 4-9.5 cm de largo; lámina 1221 x 4-9 cm, elíptica a ovado-elíptica, base obtusa a cuneada, margen subentero, crenado a esparcida y conspicuamente dentado, ápice agudo o acuminado, nervadura pinnada, glabrescente a esparcidamente puberulenta en ambas superficies, con 8 a 12 pares de nervios secundarios evidentes en el haz y en el envés, eglandulosas en el lado abaxial. Inflorescencias de largas panículas, $30-50 \times 10-20 \mathrm{~cm}$, pedúnculos $5-15 \mathrm{~cm}$ de largo, conspicuamente péndulas, ejes puberulentos. Capítulos discoides; pedicelos 1-5 $\mathrm{mm}$ de largo; brácteas involucrales en 3 o 4 series desiguales, las internas más largas, subimbricadas, oblongas a oblongo-lanceoladas, ápice agudo, menos frecuente obtuso, puberulentas principalmente hacia el margen, serie externa $1.25-1.5 \times 0.5-0.75 \mathrm{~mm}$, persistente, serie interna $4-6$ x 0.75-1 mm, fácilmente 
decidua; receptáculo 0.75-1 mm de diámetro, aplanado, cortamente pubescente; flósculos 11 a 16 , corola 6.5$7 \mathrm{~mm}$ de largo, hipocrateriforme, lila, glabra en la superficie externa e interna, lóbulos $0.35-0.5 \mathrm{~mm}$ de largo, levemente más largos que anchos, glabros, eglandulosos y papilosos en la superficie externa, lisos en la superficie interna, anteras $1.25-1.5 \mathrm{~mm}$ de largo ( $\sin$ incluir apéndice apical), apéndice $0.25-0.3 \mathrm{~mm}$ de largo, oblongo-ovado, más largo que ancho, hialino, base del estilo alargada, glabra. Aquenios 2-2.5 mm de largo, prismáticos, pentacostados, con pelos antrorsos y diminutos en las costillas; vilano una serie de 30 a
40 cerdas capilares, 5.5-6.5 mm de largo, con tamaño similar al de los flósculos, con diminutos tricomas antrorsos.

Distribución. Especie endémica en Costa Rica. Habita en bosques pluviales de la vertiente caribe de la Cordillera de Talamanca; en la vertiente pacífica se halla en Puriscal-Los Santos, a 1000 m de elevación. Fenología. Flores entre enero y febrero.

Neomirandea pendulissima se reconoce por producir 3 ó 4 hojas por nudo e inflorescencias muy largas y
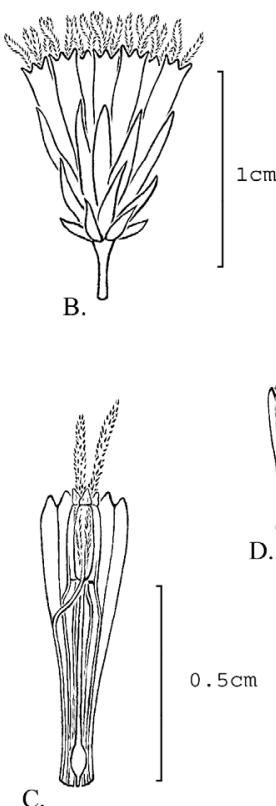

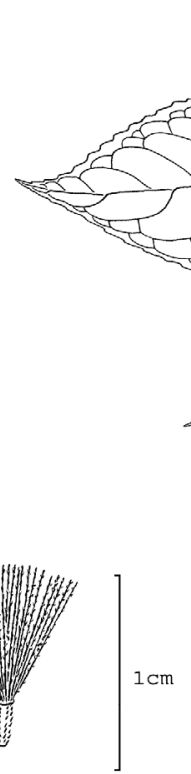

A.

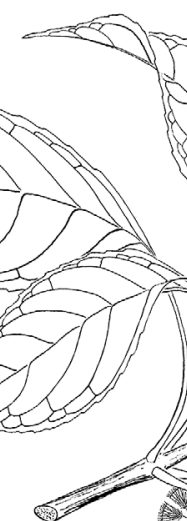

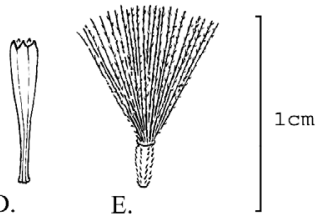

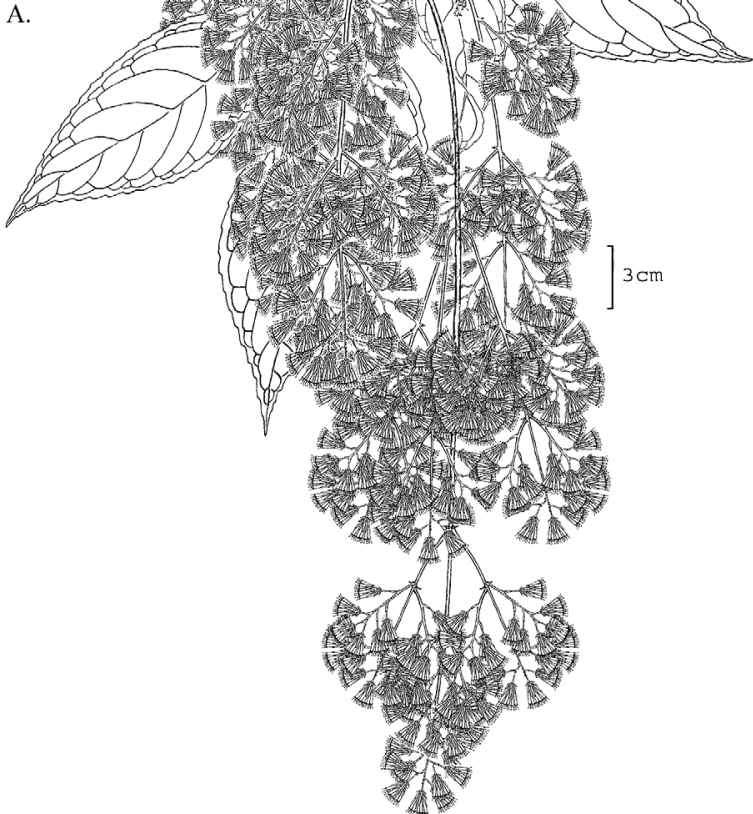

Fig. 1. Neomirandea pendulissima Al. Rodr. (L. Angulo \& IV Curso de Parataxónomos 26, INB). A. Hábito. - B. Capítulo. - C y D. Flósculo. - E. Aquenio. 
péndulas; además, se distingue por ser un arbusto epífito, por sus hojas con alargados pecíolos, con margen subentero, crenado a esparcida y conspicuamente dentado, eglandulosas en el envés, con nervadura pinnada fácilmente visible, flósculos glabros en la superficie interna, con lóbulos cortos y eglandulosos en la superficie externa, y aquenios con pelos antrorsos y diminutos en las costillas.

En este género, otras especies con hojas en verticilos son $N$. costaricensis y N. ternata R.M. King \& H. Rob.; sin embargo, estas últimas se distinguen debido a que siempre tienen 3 hojas por nudo, los pecíolos más cortos $(0.1-0.9 \mathrm{~cm})$, la lámina más pequeña $(1-10 \times 0.3-4.2 \mathrm{~cm})$ y las inflorescencias más cortas $(5-25 \times 8-20 \mathrm{~cm})$. ETimología. El epíteto latino pendulissima hace alusión a las inflorescencias conspicuamente péndulas.

Paratipo: Costa Rica. San José: Dota, Nara, 2 km camino a San Isidro, $09^{\circ} 30^{\prime} 15^{\prime} \mathrm{N}, 84^{\circ} 00^{\prime} 00^{\prime \prime} \mathrm{W}, 1000$ m, 13 ene 2003, F. Morales 10206 (CR, INB, MO).

Neomirandea psoralea (B.L. Rob.) R.M. King \& H. Rob., Phytologia 19: 308. 1970.

Eupatorium psoraleum B.L. Rob., Proc. Boston Soc. Nat. Hist. 31: 253. 1904. Neomirandea biflora R.M. King \& H. Rob., Phytologia 29(5): 351-352. 1975.

Distribución. Endémica en Costa Rica. Se le encuentra en bosques pluviales de ambas vertientes en las Cordilleras Central y de Talamanca, 2300-3000 $m$ de elevación.

Fenología. Flores entre abril y septiembre.

Neomirandea psoralea se distingue de las otras especies del género que habitan en Costa Rica por tener 3-11 capítulos sésiles o subsésiles por glomérulo, cada capítulo con 1 ó 2 flósculos; además, es un arbusto epífito, ocasionalmente escandente, con hojas enteras, eglandulosas, pecíolos alargados, entre 0.5 y $4.5 \mathrm{~cm}$ de largo, nervadura pinnada, nervios visibles, en ocasiones envés barbado en las axilas formadas entre el nervio central y los secundarios, y flósculos pubescentes en la superficie interna. Esta especie está muy relacionada con $N$. araliifolia y $N$. turrialbae; sin embargo, estas últimas poseen capítulos con pedicelos entre 2 y $9 \mathrm{~mm}$ de largo, agrupados o no en glomérulos, con mayor número de flósculos por capítulo, entre 3 y 24, lóbulos de la corola menos incisos en el limbo, aquenios glabros o con tricomas diminutos y antrorsos en las costillas (vs. glabros) y a menudo se distribuyen a menor elevación, entre 200 y 3150 m de elevación.

ESPECÍMENES REPRESENTATIVOS EXAMINADOS. COSTA RICA. Cartago: El Guarco, Reserva Forestal Los Santos, Estación Ojo de Agua, 09³7'16”N, $83^{\circ} 49^{\prime} 43^{\prime \prime} \mathrm{W}, 3000 \mathrm{~m}, 26$ jun 1997, B. Gamboa 1596 (INB). Heredia: Barva, Parque Nacional Braulio Carrillo, Cordillera Central, Estación Barva, $10^{\circ} 07^{\prime} 49^{\prime \prime} \mathrm{N}, 8^{\circ} 07^{\prime} 32^{\prime \prime} \mathrm{W}, 2680 \mathrm{~m}, 17$ sept 1994 , E. Lépiz 538 (INB); $10^{\circ} 07^{\prime} 40^{\prime \prime} \mathrm{N}, 84^{\circ} 08^{\prime} 10^{\prime \prime} \mathrm{W}$, 2630 m, 22 mayo 1990, G. Rivera 326 (INB); $10^{\circ} 07^{\prime} 22^{\prime \prime} \mathrm{N}, 8^{\circ} 07^{\prime} 15^{\prime} \mathrm{W}, 2300 \mathrm{~m}, 24$ jun 1990, G. Varela 122 (INB). Limón: Talamanca, Parque Nacional La Amistad, Tararia, Cerro Kasir y Cerro Nai, $09^{\circ} 12^{\prime} 40^{\prime}$ 'N, $83^{\circ} 04^{\prime} 04^{\prime \prime} \mathrm{W}, 3000-3100$ m, 20 jul 2000, E. Alfaro 3242 (INB).

Neomirandea standleyi (B.L. Rob.) R.M. King \& H. Rob., Phytologia 19: 308. 1970.

Eupatorium standleyi B.L. Rob., Contr. Gray Herb. 77: 40. 1926.

Eupatorium brenesii Standl., Publ. Field Mus. Nat. Hist., Bot. Ser. 18(4): 1461. 1938.

Distribución. Costa Rica y Panamá. En Costa Rica se encuentra en bosques muy húmedos y pluviales de ambas vertientes de las Cordilleras de Tilarán, Central y de Talamanca, 530-2050 m de elevación.

Fenología. Flores entre diciembre y marzo.

Neomirandea standleyi se reconoce por ser un arbusto sufruticoso, a menudo subescandente, con tallitos poco o nada lignificados, epífito o creciendo sobre troncos en descomposición, con hojas dentadas, nervadura pinnada y flósculos esparcidamente pubescentes en la superficie interna. Esta especie es muy afín a N. homogama (Hieron.) H. Rob. \& Brettell, de Panamá, Colombia y Ecuador, pero los capítulos de ésta tienen mayor número de flósculos (entre 14 y 21 vs. 5 a 12) en la mayoría de los casos, los flósculos generalmente más largos, entre 5 y $7 \mathrm{~mm}$ (vs. 4.5-5 $\mathrm{mm}$ ) y brácteas involucrales ovadas (vs. oblongas a elípticas).

EsPeCímenes RePresentativos EXAminados. COSTA RICA. Cartago: Paraíso, Parque Nacional Tapantí, entrada al Sendero Árboles Caídos, 0943'54'N, $83^{\circ} 46^{\prime} 48^{\prime \prime} \mathrm{W}, 1450 \mathrm{~m}, 18$ febr 2000, L. Acosta 343 (INB); alrededores de la estación Tapantí, $09^{\circ} 45^{\prime} \mathrm{N}$, $83^{\circ} 47^{\prime} \mathrm{W}, 1200$ m, 27 febr 1997, A. Rodríguez 2042 (INB). Limón: Pococí, Parque Nacional Braulio Carrillo, estación Quebrada González, Sendero La Palma y alrededores, $10^{\circ} 09^{\prime} 15^{\prime \prime} \mathrm{N}, \quad 83^{\circ} 56^{\prime} 15^{\prime \prime} \mathrm{W}$, 
530 m, 5 abr 1999, A. Rodríguez 4747 (INB).

Puntarenas: Puntarenas, Sendero La Catarata, por el río, 10¹6'20”N, 8449’30”W, 1100 m, 5 mar 1993, Z. Fuentes $198 A$ (INB). San José: Vázquez de Coronado, Parque Nacional Braulio Carrillo, Cordillera Central, cerca de $5 \mathrm{~km} \mathrm{~N}$ del túnel Zurquí, $10^{\circ} 06^{\prime} 10^{\prime \prime} \mathrm{N}$, $83^{\circ} 58^{\prime} 40$ ”'W, 1100 m, 5 dic 1995, B. Hammel 20007 (INB).

Neomirandea turrialbae R.M. King \& H. Rob., Phytologia 30(1): 10, f. 1975.

Distribución. Endémica de Costa Rica. Se le encuentra en bosques pluviales de ambas vertientes de las Cordilleras de Tilarán, Central y de Talamanca, 1100-3150 m de elevación.

Fenología. Flores en abril y mayo y entre agosto y octubre.

Neomirandea turrialbae se reconoce por ser un arbusto, raras veces un bejuco, epífito o terrestre, con capítulos solitarios u ocasionalmente en glomérulos de 2 ó 3 capítulos, la mayoría pedicelados, pedicelos hasta $5 \mathrm{~mm}$ de largo, con 4 a 6 flósculos pubescentes en la superficie interna, hojas enteras, eglandulosas, pecíolos alargados, entre 0.5 y $4.5 \mathrm{~cm}$ de largo, nervadura pinnada y fácilmente visible. Esta especie está muy relacionada con $N$. psoralea y $N$. araliifolia; podría considerarse como un estado intermedio entre ambas especies debido a que comparte características entre ellas. Se ha mantenido separada debido a que el número de flósculos por capítulo es constante y diferente al de las especies mencionadas antes, entre 3 y 6 por capítulo (vs. 1 ó 2 flósculos en N. psoralea y 13 a 24 en $N$. araliifolia). Además, $N$. psoralea posee capítulos siempre sésiles en glomérulos, lóbulos de los flósculos generalmente más incisos y aquenios siempre glabros (vs. diminuto-pubescentes en las costillas o glabros), mientras que $N$. araliifolia posee capítulos con mayor número de flósculos. En esta sinopsis se interpreta que $N$. turrialbae es una especie variable por la presencia o la ausencia de tricomas en la superficie externa de la corola y en los aquenios.

Especímenes Representativos examinados. COSTA RICA. Puntarenas: Coto Brus, Parque Nacional La

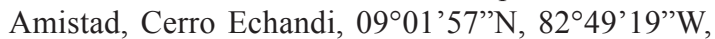
3000-3150 m, 14 abr 1998, E. Alfaro 1625 (INB); Parque Internacional La Amistad, páramo del Cerro Echandi, 0901'57'N, 82 49'19' W, 3000-3150 m, 13 ago 1997, J. Quesada 1993 (INB); Puntarenas, Reserva Biológica Monteverde, Quebrada Veracruz, $10^{\circ} 15^{\prime} \mathrm{N}, 84^{\circ} 48^{\prime} \mathrm{W}, 1600 \mathrm{~m}, 11$ ene 1990, E. Bello 1744 (INB); Cerro Ojo de Agua, Estación Leonel Hernández, $10^{\circ} 14^{\prime} 46^{\prime} \mathrm{N}, \quad 84^{\circ} 46^{\prime} 00^{\prime} \mathrm{W}, 1600 \mathrm{~m}$, 24 ago 1993, E. Bello 5241 (INB), E. Bello 5269 (INB).

Agradecimientos. El autor desea agradecer a Claudia Aragón por la preparación de la ilustración, a Francisco Morales por el aporte de nuevos especímenes y de fotografías de Neomirandea pendulissima y a Frank Almeda por su ayuda en la diagnosis latina.

\section{LITERATURA CITADA}

King, R.M. \& Robinson, H. 1970. Studies in the Eupatorieae (Compositae). A new genus, Neomirandea. Phytologia 19: 304-310. \& ---------. 1975. Studies in the Eupatorieae (Asteraceae). Two new species of Neomirandea. Phytologia 30: 9-14. \& --------. 1975. Compositae. In: Woodson, R.E. Jr. \& Schery, R.W. (ed.). Flora of Panama. Ann. Missouri Bot. Gard. 62: 981-991. \& ----------. 1985. Studies in the Eupatorieae (Asteraceae). Additional species from Tropical America. Phytologia 58 (4): 258-272. \& --------. 1987. The Genera of Eupatorieae (Asteraceae). Syst. Bot. Monogr. 22: $1-581$.

Turner, B.L. 2001. Asteraceae. In: Stevens, W., C. Ulloa, A. Pool \& O. Montiel (eds.). Flora de Nicaragua. Monogr. Syst. Bot. Missouri Bot. Gard. 85(1): 2452-2467. 